\title{
CONSIDERAÇÕES SOBRE O FINAL DE ANÁLISE
}

\section{Maria Thereza Ávila Dantas Coelho}

Resumo: Na comunidade psicanalítica, o tema do final de análise sempre permeou a discussão técnico-teórica. Na Escola Lacaniana, especificamente, esse tema adquiriu especial interesse a partir do momento em que Lacan propôs um novo dispositivo de transmissão, o passe, para que novos analistas testemunhassem sobre a sua passagem à condição de analista. Desde então, diferentes concepções lacanianas sobre o final de análise têm surgido e produzido nova discussão. É nesse contexto que este artigo visa a contribuir com esse debate atual, discutindo diversos aspectos, tais como a eficácia da análise, as vicissitudes da transferência e da pulsão no processo analítico, a re-análise e o dispositivo do passe. Para tanto, parte, inicialmente, das questões levantadas pelo texto freudiano "Análise terminável e interminável" e as discute à luz dos desenvolvimentos teóricos realizados por analistas lacanianos. Após apresentar diferentes concepções sobre o final de análise, o artigo defende que há, nesse processo, um ponto de irredutibilidade, a partir do qual se é convocado a uma produção singular.

Palavras-chave:Término da análise. Transferência (Lacan). Psicanálise clínica.

\section{Introdução}

Este trabalho tem por objetivo refletir o tema do final de análise tanto a partir do texto freudiano "Análise terminável e interminável" quanto a partir dos desdobramentos teóricos realizados pela Escola Lacaniana. Apesar desse tema ser freqüentemente discutido no âmbito das instituições psicanalíticas, é notório a sua ausência entre os principais periódicos científicos nacionais. Tal lacuna incita a investigação 
teórica, uma vez que a discussão sobre o final de análise é essencial para o campo da clínica e da formação profissional. O ponto de partida de tal discussão é, então, o emblemático texto "Análise terminável e interminável", publicado por Freud em 1937, que tem se mostrado infindavelmente passível de novas articulações. Iniciaremos a discussão problematizando a eficácia da análise e, a seguir, discorreremos sobre as vicissitudes da transferência e da pulsão no decorrer do processo analítico. Posteriormente, abordaremos as questões levantadas pelos processos de re-análise e pela proposição lacaniana do passe.

\section{A eficácia da análise}

Sabemos que James Strachey, o editor inglês das Obras Completas de Sigmund Freud, considerou que o pai da Psicanálise deu uma impressão de pessimismo em seu texto "Análise terminável e interminável" (Strachey 1969/1980), abandonando o otimismo que, até então, o alimentara quanto à eficácia da análise (Freud, 1917/1980). É provável que muitos fatores, de diferentes ordens, tenham influenciado essa mudança. Entretanto, seria ela da ordem do pessimismo? A conjunção e, no título do texto, é um indicativo da posição freudiana quanto ao final de análise: por um lado ela termina, por outro não. Se Freud assinalou aí as limitações e dificuldades do processo analítico, também sublinhou seus avanços (Freud, 1937/1980). Afirmou, por exemplo, que uma análise termina quando o paciente não mais sofre de seus sintomas, superou suas ansiedades e inibições, e o analista julgue que "foi tornado consciente tanto material reprimido, que foi explicada tanta coisa ininteligível, que foram vencidas tantas resistências internas que não há necessidade de temer uma repetição do processo patológico" (Freud, 1937/1980, p. 251). Relativizando, então, os diversos pontos de vista defendidos por Freud, em momentos diferentes, podemos sustentar que, em alguns casos, a análise contribui para o não-retorno ou a não-ocorrência de certos sintomas neuróticos, embora sempre vá haver uma dimensão irredutível do sintoma. Assim, não se trata de defender uma posição otimista ou pessimista, afirmando ou negando efeitos permanentes da análise, porque, mesmo nos casos em que o sintoma insiste, isso, a princípio, não é um critério de ineficácia. Colocar a ausência de uma nova manifestação neurótica do lado do otimismo, e sua ocorrência do lado do pessimismo, parece ser uma simplificação inadequada de um processo cujas diretrizes são de outra natureza. Não se trata, aqui, simplesmente ou necessariamente, de erradicar o sintoma, como persegue o modelo médico, embora isso também possa acontecer. Manter uma nova relação com a dimensão sintomática já bem pode ser indicativo da eficácia de um processo analítico, eficácia esta sempre variável, a depender de cada caso. Nesse sentido, o valor essencial da mudança empreendida por Freud, em seu texto Análise 
Terminável e Interminável, reside na perspectiva segundo a qual o fim da análise implica o processo de luto não só da análise perdida, mas, também, das ilusões que a alimentavam.

As considerações acerca da eficácia e do final de análise são, portanto, o principal aspecto discutido por Freud em seu texto "Análise terminável e interminável." Logo no primeiro capítulo, ele admitiu ter se enganado em sua crença na cura permanente de um ex-paciente: o Homem dos Lobos (Freud, 1937/1980). Nesse caso, a fixação do tempo de duração da análise mostrou ser um recurso inadequado para a condução do tratamento. Se, por um lado, fez acelerar o processo analítico, por outro o fez ser interrompido antes do seu fim. Tal manejo do tempo, adotado posteriormente por alguns analistas, não pode refletir, em alguns casos, uma resistência do analista ao processo de análise? Sobre esse aspecto, Zuberman (1992) refere que não se trata, simplesmente, de não enunciar esse fim, mas de discutir qual é a melhor morte: a súbita ou a que se produz lentamente. Para ele, a previsão do término de análise protege mais o analista do que o analisando. Não creio que isso possa se generalizar. De qualquer modo, cabe interrogar se o prévio anúncio do fim é capaz de evitar ou minorar o impacto, a surpresa, o excesso que o término da análise pode comportar.

\section{As vicissitudes da transferência e da pulsão}

Uma outra questão que a análise do "Homem dos lobos" faz pensar é se toda análise é passível de terminar. Segundo Freud, algumas das crises posteriores ao suposto final de análise do "Homem dos lobos" se deveu a partes residuais da transferência, que apresentavam um caráter distintamente paranóico (Freud, 1937/1980). Ainda que não discutamos aqui o diagnóstico desse paciente ou o final de análise na psicose, podemos questionar se a entrada ou a saída da análise pode ser definida a priori, com base na estrutura. Não seria melhor tratar disso em cada caso, já que há variações? Sabemos que só pode haver saída desse processo se houver tido entrada e que, uma vez ocorrida a entrada, operações analíticas precisam se processar para que a análise chegue a seu fim.

As partes residuais da transferência do Homem dos Lobos remetem à questão das vicissitudes da transferência no transcorrer e no final de análise. Diversos autores da Escola Lacaniana têm se debruçado sobre essa questão. Para Lacan, após o analista ser colocado na posição de sujeito suposto saber pelo analisando, ele é destituído dessa posição e, posteriormente, cai enquanto representante do objeto a (Lacan, 1967-1968). Isso implica, de um lado, uma mudança na relação com o saber e, de outro, um atravessamento da fantasia, pois o analista deixa de sustentar, com sua presença, o fantasma de seu analisando. Para Zuberman (1992), essa operação possibilita ao analisando gozar dos objetos de seu desejo, se ele assim o 
quiser. A queda do analista da posição de objeto $a$ é mais radical do que a sua queda da posição de sujeito suposto saber, na medida em que, tal como uma morte, ela propicia uma separação mais definitiva. Entretanto, o fim da análise não é sem resto, não é sem sintoma. Nele, o analisando deixa de se interrogar, de se queixar do seu sintoma, e se identifica com ele (Lacan, 1975-1976/2007, 1976-1977;Pommier, 1986;Soler, 1995). Isso ocorre após o sintoma ter sido desprovido de seus aspectos imaginários e simbólicos e ter sido reduzido ao seu núcleo real de gozo. Assim, se de um lado, a análise produz um abalo ou faz cair as identificações imaginárias e simbólicas do sujeito, de outro, ao final, produz uma identificação real ao sintoma, não alienada ao Outro. Tal operação implica assumir, aceitar a inércia do sintoma e o que sobra dele no final de análise. Implica, ainda, reconhecer e lidar com o modo de gozo central do sujeito, o que foi traduzido por Lacan pela expressão "saber haver com o seu sintoma" (Lacan, 1975-1976/2007, 1976-1977).

Ainda que Freud não tenha se detido na formalização das vicissitudes da transferência ao longo do processo de análise, se observarmos atentamente o texto "Análise terminável e interminável" veremos que, nele, de certo modo, Freud abordou esse aspecto, ainda que de forma diferente. Ele defendeu que, no final da análise, o analisando tanto pode aceitar e consentir com um modo de satisfação pulsional que, até então, ele havia rejeitado, quanto, também, pode renovar essa rejeição e produzir um novo recalque, mais bem sucedido (Freud, 1937/1980). Nesse último caso, não há, entretanto, garantia de que, diante de novas situações e exigências pulsionais, o recalcado não retorne. Essa pode ser uma das razões pelas quais Lacan considerou que a identificação ao sintoma é o melhor que pode acontecer a alguém, em seu final de análise (Soler, 1995). Freud está tratando, aí, de uma operação que não se dá, simplesmente, no nível do saber, mas que implica a adoção de uma posição no nível do querer. Ele não escolhia por seus pacientes, transmitindo uma ética que, mais tarde, foi compartilhada por Lacan. Verificamos, entretanto, que Freud não considerou a possibilidade da análise transformar a exigência pulsional do sujeito, mas apenas a possibilidade do analisando rever a sua posição em relação a ela. Lacan foi mais além: considerou que a identificação ao sintoma tanto pode implicar uma resignação e aceitação do gozo, tal como ele é, quanto pode promover uma mudança efetiva no nível do próprio gozo. No primeiro caso, não há uma mudança substancial do sintoma, mas da perspectiva que se tem dele, ao contrário da segunda situação, em que muda o próprio sintoma. Considerando que toda análise é um processo singular, a posição lacaniana parece bastante apropriada para tratar das vicissitudes da transferência e da pulsão, já que ela admite a perspectiva freudiana e vai mais além, ampliando as possibilidades de transformação para o analisando. 


\section{A re-análise}

Voltemos à análise do Homem dos Lobos. Se a retomada desse processo foi percebida, por Freud, como conseqüência de um equívoco seu quanto ao final de análise, não foi desta maneira que ele abordou o tema da re-análise dos analistas (Freud, 1937/1980). A forma diferenciada com que tratou essa questão em relação a analistas e não-analistas remete a uma distinção feita por ele entre, de um lado, a análise didática e, de outro, as análises terapêutica e de caráter. Em "Análise terminável e interminável", Freud ofereceu dois tipos de finais de análise distintos, conforme o tipo de análise. Ele ressaltou o caráter breve da análise didática, em contraposição às análises terapêutica e de caráter, e tratou o seu término como uma questão de ordem prática. Considerou que ela realiza seu intuito quando fornece uma convicção firme da existência do inconsciente, capacita a perceber o material reprimido e mostra um primeiro exemplo da técnica psicanalítica. Freud ressaltou que essa análise não era suficiente para a formação do analista, sendo necessária, após o seu término, a continuidade desse processo através de uma auto-análise espontânea. Recomendou, ainda, que o analista se submetesse, periodicamente, a uma re-análise, uma vez que a prática clínica desperta, nele, impulsos inconscientes. Se Freud entendia que a análise do analista só podia ser breve, e acreditava na continuidade desse processo através da auto-análise, por que recomendou, então, re-análise periódica? Se ele percebeu os limites da auto-análise, por que considerou que a análise didática só podia ser breve?

Quanto ao final de análise de não-analistas, Freud afirmou que, nele, o analisando se depara com o complexo de castração na transferência (Freud, 1937/1980). Nesse contexto, ele distinguiu o final de análise em função da diferença entre os sexos. Afirmou que as mulheres se deparam com a frustração de não ter recebido o pênis do analista e deprimem, e os homens lutam contra uma atitude passiva em relação ao analista e se recusam a aceitar dele seu restabelecimento. Homens e mulheres se deparam, portanto, com o repúdio da feminilidade. A realização de uma outra análise, nesses casos, corresponde ou à retomada da análise interrompida, ou ao trabalho analítico de conflitos que não se encontravam ativos na análise anterior. Essa segunda hipótese freudiana é paradoxal, na medida em que, de acordo com sua teoria, todo conflito é, a princípio, ativo, ainda que não esteja manifesto.

Freud terminou o seu texto Análise Terminável e Interminável com uma incerteza. Ele não colocou o complexo de castração como uma barreira intransponível no final de análise, mas sim como um impasse, ressaltando a possibilidade do analisando vir a reexaminar e mudar a sua atitude em relação a ele. Entretanto, se nesse ponto Freud vacilou, o mesmo não se deu com Lacan, para quem a castração não constitui um limite ou impasse do final de análise (Lacan, 1962-1963/2005, 1965-1966). 
A divisão freudiana entre análise didática, análise terapêutica e análise de caráter não foi mantida por Lacan. A partir da teorização lacaniana sobre o desejo do analista, toda análise que chegue a seu fim produz um analista, ainda que o ex-analisando não venha a exercer tal ofício (Lacan, 1968/2003). Dentro do movimento lacaniano, algumas posições acentuam a relação entre o tornar-se analista e o final de análise (Nasio, 1993; Yankelevich, 1993), enquanto outras marcam, justamente, a relação entre a prática clínica e a sua infinitude (Calligaris, 1993; Dolto, 1993). No que diz respeito à re-análise, enquanto alguns analistas defendem a sua ocorrência após o final de análise (Yankelevich, 1993; McLaughlin citado por Indart et al., 1995), outros assinalam que isso seria um indicativo de que a análise anterior não finalizou (Nasio, 1989/1993; Dellarosa, Abuchain \& Garma citados por Indart et al., 1995). Verificamos, assim, a existência de uma vertente mais ligada à posição freudiana, e outra mais sintonizada com o pensamento inovador de Lacan. Entretanto, parece-me que essa questão não deve ser tratada sob o prisma dualista da "posição freudiana" versus "posição lacaniana",mas, sim, sob o contexto da singularidade de todo processo de análise. Nessa perspectiva, não se pode generalizar que a re-análise seja necessariamente um sinal de que a análise anterior não foi terminada, embora isso também possa ocorrer, nem que o não-retorno a um segundo processo de análise seja um sinal de que a primeira análise foi concluída. Cada processo só pode ser analisado dentro de sua singularidade, a partir de sua transmissão a outros analistas.

\section{O passe}

A proposição lacaniana de que um final de análise produz um analista rompeu com os padrões de formação exigidos pela IPA e produziu uma nova associação de psicanalistas. A partir de então, a questão do final de análise adquiriu amplitude, ligando-se ao problema do passe. Quando Lacan instituiu esse dispositivo, quando propôs que se colhessem testemunhos sobre o final de análise, estava interessado, sobretudo, na fala e escrita da passagem da condição de analisando à condição de analista. Sabemos que essa passagem está além da terapêutica e não se reduz ao exercício do ofício de psicanalista, pois nem todos que terminam sua análise se colocam na posição de analista para um outro. Trata-se, aí, essencialmente, de uma transformação subjetiva. Mas qual o estatuto desse novo sujeito?

Para Freud, não é possível decidir entre as duas proposições seguintes: 1) "aquilo que a análise realiza para os neuróticos nada mais é do que aquilo que as pessoas normais ocasionam para si próprias sem o auxílio dela" (Freud, 1937/1980, p. 257); 2) "a análise produz um estado que nunca surge espontaneamente no ego",e isso"constitui a diferença essencial entre uma pessoa que foi analisada e outra que não o foi" (p. 259). Por que Freud 
considerava não ser possível decidir entre essas duas proposições? O que elas significam? A dificuldade em optar por uma dessas alternativas parece estar ligada à diferença de natureza entre elas. A primeira inclui aspectos operacionais da vida, enquanto a segunda está mais ligada a processos intrapsíquicos. Ambas portam uma verdade, já que, de um lado, algumas pessoas que não passam por um processo de análise realizam, com certa facilidade, atividades que outros só conseguem após um processo de análise, e, de outro lado, a análise implica vencer certas barreiras internas que dificilmente poderiam ser ultrapassadas sem ela. É interessante observar que a primeira proposição freudiana retira o psicanalista de uma categoria à parte, na medida em que ele não se torna um indivíduo diferente do homem normal comum. A segunda proposição, por sua vez, marca uma diferença qualitativa entre o indivíduo que finalizou sua análise e aquele que não o fez. Lacan seguiu, justamente, nessa direção (Lacan, 1968/2003). A sua tese de que o final de análise produz um analista e faz emergir um novo desejo aponta para uma diferença radical entre esses dois grupos.

Um dos aspectos criticáveis na primeira proposição freudiana é que ela torna homogêneo o grupo das pessoas que não procuram análise. Seriam todos esses indivíduos tão saudáveis e normais assim? Constituir-seiam eles num parâmetro para o final de análise? Creio que não. Convivemos, em nosso dia-a-dia, com muitas pessoas que não realizam um processo de análise, mas que, nem por isso, estão isentas de grande sofrimento psíquico, nem se consideram ou são consideradas como saudáveis pelos demais. Há, entretanto, um aspecto relevante nessa primeira perspectiva de Freud, que merece ser abordado. $O$ seu valor reside não na homogeneização, ao final, entre os dois grupos de pessoas (analisados e não-analisados), mas na desidealização da figura do psicanalista. A teorização de Lacan sobre a queda do analista da posição de sujeito suposto saber, por exemplo, atualiza, de certa forma, essa operação de desidealização apontada por Freud. Ainda que o analista porte, em sua diferença, o desejo do analista, ele não se coloca como um modelo ideal, com o qual o analisando se identifica ao final de sua análise. Assim, a diferença entre analistas e não-analistas não diz respeito à questão da normalidade, mas à possibilidade de se ocupar a posição de analista para um outro. Nisso reside um dos pontos essenciais da transmissão da Psicanálise. O passe, enquanto um dispositivo de transmissão, busca, então, dar conta dessa passagem da condição de analisando à condição de analista.

\section{Considerações finais}

Partindo inicialmente do texto freudiano "Análise terminável e interminável" e de desenvolvimentos teóricos realizados por analistas lacanianos, esse artigo discutiu algumas questões atuais no debate sobre o final 
de análise, dentre elas a eficácia da análise, as vicissitudes da transferência e da pulsão no processo analítico, a re-análise e o dispositivo do passe. Ao longo da discussão dessas questões, verificamos que um aspecto se tornou essencial: a dimensão singular do processo de análise. Nessa direção, é importante considerar que o término de uma análise pode ter lugar justamente quando a questão do seu fim não é colocada nos mesmos moldes em que ela vem sendo tratada pela teoria. No que diz respeito a esse aspecto, Salvain sublinhou que o final de análise pode se dar, justamente, quando ele não é pensado nos termos da travessia do fantasma ou do luto do objeto a (Salvain, 1993). Afinal, não estaria aí a essência da proposição de Lacan sobre o passe, qual seja pensar o final de análise de forma única?

Tal perspectiva não significa, porém, que a travessia do fantasma ou o luto do objeto a não ocorram num final de análise. Significa, sim, que cada final possui uma singularidade, que pode vir a ser abordada. A depender da produção analítica de cada analisando, da condução da análise por parte de cada analista e da leitura teórica que se faça de cada processo, diversos aspectos do final de análise podem ser delineados. Também há, nesse processo, algo que escapa e que lhe é irredutível. É justamente a partir desse ponto indecifrável que somos convocados a inventar, ou seja, a realizar, uma produção teórica também singular.

\section{Considerations about the end of analysis}

Abstract: In the psychoanalytic community, the end of analysis has always concerned the argument theoretical-technical. In the Lacanian School especially, the end of analysis acquired special attraction when Lacan proposed a new transmission's gadget, the pass, whereby new analysts tell us about their passage to analyst condition. Ever since, different conceptions of the end of analysis have appeared and produced a new discussion. In this context this article contributes to the present argument, discussing various aspects like efficacy of analysis, destinies of transference and instinct, second analysis and pass. In order to do so, part of the initially queries raised by the Freudian text Finished and Unfinished Analysis and discusses them by the theoretical developments accomplished by Lacanian analysts. After it presents different conceptions about the end of analysis, it defends a final point, whereby we are called to invent, to make a singular production.

Keywords: End of analysis. Transference (Lacan). Psychoanalysis clinic. 


\section{Considérations sur la fin de analyse}

Résumé: Dans la communauté psychanalytique, le thème de la fin de analyse toujours imprégné la discussion technique et théorique. Dans l'école lacanienne,précisément,cette question a acquis un intérêt particulier a partir du moment où Lacan a proposé un nouveau mécanisme de transmission, la passe, de sorte que les nouveaux analystes témoignage sur l'état de leur passage à l'analyste. Depuis lors, les conceptions différentes sur la fin de la analyse lacanienne ont vu le jour produit les nouvelles discussions. C'est dans ce contexte que cet article vise à contribuer à ce débat aujourd'hui, à discuter divers aspects tels que l'efficacité de l'analyse, les vicissitudes du transfert et de pulsion dans le procès analytique, la ré-analyse et la procédure de la passe. Pour cela, initialement partie des questions soulevées par lo texte freudien Analysis Terminável et sans Fin et les examine la lumière des développements théoriques faites par les analystes lacanienne. Après la présentation des idées différentes sur la fin de l'analyse, l'article fait valoir que existe, dans ce procès, un point de irrémédiable, a partir de laquelle elle est appelée à une production unique.

Mots-clés: Fin de analyse. Transfert (Lacan). Psychanalyse clinique.

\section{Consideraciones acerca del final del análisis}

Resumen: En la comunidad psicoanalítica, el tema 'final del análisis' siempre habitó la discusión técnica y teórica. En la Escuela Lacaniana, específicamente, ese tema ganó especial interés desde el momento en que Lacan propone un nuevo mecanismo de transmisión, el pase, de modo que los nuevos analistas presten testimonio acerca de la condición de su pasaje al analista. Desde entonces, diferentes concepciones acerca del final del análisis lacaniano han surgido y producido nuevo debate. Es en ese contexto que este artículo tiene por objetivo contribuir con este debate de hoy, discutir diversos aspectos, tales como la eficacia del análisis, las vicisitudes de la transferencia y del instinto en el proceso analítico, el re-análisis y el dispositivo del pase. Para eso, inicialmente parte de las cuestiones planteadas por el texto freudiano Análisis Terminable y Interminable y las analiza a la luz de los desarrollos teóricos hechos por los analistas lacanianos. Después de presentar diferentes ideas sobre el fin del análisis, el artículo sostiene que hay, en ese proceso, un punto de irreductibilidad, a partir del cual se llama a una única producción.

Palabras clave: Final del análisis.Transferencia (Lacan). Psicoanalisis clinica. 


\section{Referências}

Calligaris, C. (1993). Controvérsia: Contardo Calligaris/Patrick Salvain. In A. DidierWeill (Org.), Fim de uma análise, finalidade da psicanálise (pp. 79-92). Rio de Janeiro: Jorge Zahar.

Dolto, F. (1993). Controvérsia: Françoise Dolto/Hector Yankelevich. In A. Didier-Weill (Org.), Fim de uma análise, finalidade da psicanálise (pp. 116-144). Rio de Janeiro: Jorge Zahar.

Freud, S. (1980a). Conferência XXVII - Transferência. In S. Freud, Edição standard brasileira das obras psicológicas completas de Sigmund Freud (Vol. 16, pp. 503-521). Rio de Janeiro: Imago. (Trabalho original publicado em 1917)

Freud, S. (1980b). Conferência XXVIII - Terapia analítica. In S. Freud, Edição standard brasileira das obras psicológicas completas de Sigmund Freud (Vol. 16, pp. 523-539). Rio de Janeiro: Imago. (Trabalho original publicado em 1917)

Freud, S. (1980). Análise terminável e interminável. In S. Freud, Edição standard brasileira das obras psicológicas completas de Sigmund Freud (Vol. 23, pp. 239-287). Rio de Janeiro: Imago. (Trabalho original publicado em 1937)

Indart, J. C. (1995). A re-análise: uma abordagem crítica. In Associação Mundial de Psicanálise (Org.), Como terminam as análises (pp. 89-94). Rio de Janeiro: Jorge Zahar.

Lacan, J. (1965-1966). O seminário. Livro 13 - O objeto da psicanálise. Inédito.

Lacan, J. (1967-1968). O seminário. Livro 15 - O ato psicanalítico. Inédito.

Lacan, J. (1976-1977). O seminário. Livro 24 - L'insu que sait de l'une bévue s'aile à mourre. Inédito.

Lacan, J. (2003). Proposição de 9 de outubro de 1967 sobre o psicanalista da escola. In J.-A. Miller (Org.), Outros escritos (pp. 248-264). Rio de Janeiro: Jorge Zahar. (Trabalho original publicado em 1968)

Lacan, J. (2005). O seminário. Livro 10 - A angústia. Rio de Janeiro: Jorge Zahar. (Trabalho original publicado em 1962-1963)

Lacan, J. (2007). O seminário. Livro 23 - O sinthoma. Rio de Janeiro: Jorge Zahar. (Trabalho original publicado em 1975-1976)

Nasio, J. D. (1993). Controvérsia: J. D.Nasio/Conrad Stein. In A. Didier-Weill (Org.), Fim de uma análise, finalidade da psicanálise (pp. 172-191). Rio de Janeiro: Jorge Zahar.

Pommier, G. (1986). Questiones (sobre el fin de análisis). Buenos Aires: Catálogos.

Salvain, P. (1993). Controvérsia: Contardo Calligaris/Patrick Salvain. In A. Didier-Weill (Org.), Fim de uma análise, finalidade da psicanálise (pp. 79-92). Rio de Janeiro: Jorge Zahar.

Soler, C. (1995). Variáveis do fim da análise. Campinas, SP: Papirus.

Strachey, J. (1980). Nota do editor - Análise terminável e interminável. In S. Freud, Edição standard brasileira das obras psicológicas completas de Sigmund Freud (Vol. 23, pp. 241-246). Rio de Janeiro: Imago. (Trabalho original publicado em 1969) 
Yankelevich, H. (1993). Controvérsia: Françoise Dolto/Hector Yankelevich. In A. Didier-Weill (Org.), Fim de uma análise, finalidade da psicanálise (pp. 116-144). Rio de Janeiro: Jorge Zahar.

Zuberman, J. A. (1992). El dispositivo del pase: fin de análisis más allá del analista, en los limites del psicoanálisis. In Escuela Freudiana de Buenos Aires (Org.), Cuadernos Sigmund Freud - 15. Buenos Aires: Nueva Vision.

Maria Thereza Ávila Dantas Coelho, Docente Titular da Universidade Salvador UNIFACS e membro do Colégio de Psicanálise da Bahia.Endereço para correspondência: Alameda das Espatódias, s/n, Caminho das Árvores, Salvador, BA. CEP 40000-000. Endereço eletrônico: therezacoelho@pop.com.br 
